\title{
NEEDS OF TERRORIST
}

\author{
Alexander Sh. Tkhostov, \\ Konstantin G. Surnov \\ Moscow State University \\ Moscow
}

This article reveals the motives of the terrorist activity. It analyzes psychological mechanisms of basic human needs that are implemented at different stages of involvement in terrorist organizations. The authors also discuss the causes of psychological attractiveness / desirability of terrorism in the context of influence of modern technologies on the dynamics of norm and pathology standards.

Keywords: psychology of terrorism, modern technologies, culture and pathology, personal psychology, motivation, basic needs.

Terrorism is one of the most painful problems in modern society, ones that call into question the very foundations of its existence. The events of the last few decades have demonstrated its total, all-pervading nature that has practically changed the modern world. While earlier terrorism was a sufficiently local problem that concerned (either geographically or economically) some limited areas, social strata or ethnos, today not a single person can feel protected enough from omnipresent terrorists. Instead of the "end of history" and a transition to a mellow existence in a reason-governed and liberal society, as predicted by Francis Fukuyama, (Fukuyama, 2002) the world finds itself in a situation of total warfare. Rather than being confined to a narrow battlefield and the knightly rules of classical war-making, it has found itself in a situation where there are no rules at all and where any person can be targeted at any moment, in any place. Where there is no logic, there are no permanent enemies or dedicated defenders. Danger lurks where you cannot expect it, and there are no reliable methods of defense. But Fukuyama based his reasoning on the quite sound postulate that the democratic idea and liberal economy had certainly proved their superiority, and,

This work was supported by 08-06-00596a grant from Russian Humanitarian Scientific Foundation. 
accordingly, people enlightened by this idea should renounce unreasonable behavior that, properly speaking, is what "history" is all about. The "end of history" is the end of irrationality.

But the predicted end of history has failed to materialize, as has the triumph of the Prussian monarchy that Hegel saw as an equally perfect model of society. For the same reason, crime failed to disappear after the Bolsheviks had uprooted its social causes. All those events have not come to pass because man has proved anything but a rational being abiding by the laws of logical and economic expedience. Rather, he is an odd creature guided by irrational fears, envy, craving for preeminence and power, and other extra economic categories. The error consists in ignoring what is properly human, i.e., things biased and extra rational by definition, while man has once again been reduced to a sum total of social relationships.

Instead of the promised idyll, there are symptoms of a growing chaos and of the end of history, albeit in a totally different sense. Terrorism as a phenomenon of contemporary history is one of the key phenomena of that end.

Terrorism is analyzed within different investigative paradigms by methods of different scientific disciplines, which is quite correct because it can well be regarded as a form of political, economic, military, criminal and other activities directed at achieving certain goals in order to satisfy need states. Of course, there are social, economic, and religious roots of terrorism, but for us it is important to identify the specifically psychological component of this problem. It is already contained in the goal definition itself: selection principles (how goal-setting is made), the level of awareness, how a declared goal tallies with the real one, and an understanding of what is really behind declared goals and what needs it is related to. In a nutshell, via which psychological mechanisms, to use Karl Marx's expression, does it grip the masses to become a material force?

The economic and social root-causes of terrorism are hopelessness, misfortunes and despair making certain people sacrifices human lives, their own included, in a bid to achieve some radical changes.

The initiating agents are poverty, unemployment, illiteracy, housing shortages, inadequacies in the education and personnel training systems, lack of prospects in life, aggravation of social inequalities, the weakening of family and social ties, alienation, ill-breeding, negative consequences of migration, erosion of cultural originality, marginaliza- tion of the population, collapse of man's self-identity, and media propaganda of ideas and views favoring violence, inequality and intolerance.

But to understand the psychological factors that make terrorist activities an individual choice for a separate person, it is necessary to understand how a social and economic phenomenon becomes a psychological study unit. Of course, that poverty, unemployment, ignorance, low socioeconomic status, etc., are a nutrient medium for terrorism is a real fact that has been recorded in numerous studies (Horgan, 2005; Hudson, 2005; Milgram, 1963; Stout, 2004). But upon becoming a terrorist, the person (here we do not mean a thin stratum of leaders) does anything but upgrade the prosperity and education level of the population, or solve unemployment problems. Poverty itself, if we do not mean the reduced capacity to satisfy the most basic survival needs, is sooner a socioeconomic than psychological factor. It becomes a psychological one to the extent to which it mediates (impedes or facilitates) fulfillment of certain different actualized needs, such as self-fulfillment, self-respect, power, etc. As a psychological technology, terrorism makes it possible to find a "bypass": poverty is not abolished but a terrorist acquires supreme power over some much richer, more successful or educated persons. The need states are satisfied in a peculiar, "displaced," symbolic form. It is in this displaced and expanded symbolism that terrorism's main "temptation" lurks: it enables one to abolish the "reality principle" (Bergeret, 2000; De Mijolla, 2002) and to satisfy one's needs by using some outwardly simpler and effortless ways.

For all their seeming distinctness from the "peaceful" methods whereby urgent sociopsychological and individual-psychological problems facing a personality and socium as a whole are addressed, terrorism's technologies have all the attributes typical of other modern need satisfaction technologies: illusory simplicity, easiness, immediacy of results, and clarity of actions and benefits.

The structure of thereby initiated activities and their cognitive-behavioral concept are as a rule simple, even primitive, and do not require more than two or three successive steps to solve a problem no matter how complicated. Neither do they require any specialized (aside from demolition works) competence, skills, techniques, or prior qualifications. Despite its destructive nature, the suggested type of need states gratification should be qualified as illusory compensatory rather than activity-related one. 
We follow Aleksey Leont'ev $(1959 ; 1975)$ in using the term need states to mark the specifics of a no objectified need, which is characterized by the lack of a fixed gratification method and is a nexus between a psychological phenomenon proper and a physiological functional state.

An individual's need state subjectively perceived as a feeling of discomfort, need, lack of something necessary and desirable for normal life, including its higher psychic level, is necessarily objectified and gratified with the help of some or other material or ideal objects in a world accessible to a given individual.

An object that represents a thing needed is routinely described as a motive of activities. A motive has stimulating and meaning-forming functions whose unity secures the necessary activity directed at finding a need gratification method. It makes the activity reasonable and intelligible and turns it into human activity proper.

Owing to their object concreteness, motives influence need states, shaping them in line with their objective qualities. The way how a need is satisfied with the help of a motive and how amply the motive satisfies some or other aspects of the need it objectifies inevitably leads to a change in the need state itself, something that in turn generates the necessity of new objectifications of a changed need with new motives. Any need state can be gratified by numerous different methods and objectified by numerous very different motives.

Let us reiterate that from a psychological point of view, terrorism is primarily a technology or a set of technologies making it possible to satisfy, by a specific method, any inherently human need states. These can be very needs of different levels, from basic ones-death drive, aggression, physiological needs, need for security and protection, need for affiliation, need for strong new impressions-to higher ones, like communication, self-fulfillment, or a striving for power, love, a quest for the meaning of life, and a desire for eternal salvation (soteriological needs).

Moreover, some technologically developed terrorist doctrines can not only provide but also actively impose well-elaborated, at different levels, methodologies and tools for objectifying the need states, turning them into well-formed and strictly determined needs of different levels.

It is this capacity to effectively satisfy various needs of different levels that turns terrorism's technologies into a universal method that makes all wishes come true, conveys to terrorism its subjective glamour, and con- stitutes a crucial vector in a psychological analysis of the phenomenon of terrorism.

To our mind, a considerable part of current terrorist psychology studies are deficient in that they ascribe an excessive importance to negative socioeconomic and psychological factors and underestimate positive motivations of terrorist activities. Let us consider how terrorist activities can objectify need states and the needs, desires, drives, and attitudes formed by a number of factors, including terrorist activities themselves.

Death drive and aggression. Current "humanistic" psychology tends to disregard these fundamental human needs. According to an optimistic view attributable to the traditions of the Enlightenment, whatever evil there is in man is due to the influences of an unfavorable environment. This is why it can be removed if favorable conditions for development are created, while an ideal society is able to do away with it altogether. The pessimistic view characterizing psychoanalysts and ethnologists is based on the assumption that the death drive and aggression are fundamental and basically ineradicable human qualities associated with some factors that are significant evolution-wise. According to the optimistic view, the universal remedy is developing tolerance that is often understood as a variant of Stanislaw Lem's betarization. As we see it, a better solution is understanding tolerance as the channeling of aggression into some socially acceptable forms, rather than the suppression of aggression. Terrorism in this case is a socially unacceptable, if extremely effective, form of basic aggressiveness camouflaged by various psychological defenses (Bergeret, 2000; De Mijolla, 2002). Projection enables one to detect an enemy, ascribing to him one's own fears, desires and plans; rationalization justifies one's own drives by the obvious expediency of their manifestations that become noble and justified. Splitting makes the world appear as the Manichaean opposition of the absolute good and the absolute evil, and, thus, despite its complex and diverse nature, it turns into a system of binary oppositions, like good-evil, sacralprofane, chosen-rejected, and, most importantly, friend-foe.

The fact that it offers a chance to gratify those drives makes terrorism subjectively a particularly attractive thing for persons with a high level of basic aggressiveness, or for those enjoying fewer opportunities for standard socialization. But even if it can be channeled into some socially acceptable forms (professional militaries, policemen, guards, athletes), the no socialized variants are all the same more attractive for 
some persons, because by definition they are less regimented. In the final analysis, even a military man is a civil servant and has to obey the strict rules of subordination, while a terrorist can identify himself with a noble avenger foreign to all restrictions of this earthly world. Of course, the case in point is his subjective representations as regards his place and role in certain concrete events rather than the reality where an ordinary terrorist is a pawn in complicated games he knows nothing about.

While we are discussing the psychological function of terrorist activities, it can be stated that they are polyvalent even where the gratification of the most archaic needs is involved, which means they can satisfy numerous different-level needs. In this particular case, they not only gratify aggressive drives but also amend them with sentiments suggesting that one is chosen, noble, etc.

Affiliation and communication need. Participation in a terrorist organization secures a reliable gratification of the basic human need to belong to a certain group and to establish emotional contact. Going beyond one's own singularity in this case is not aimed at gaining security. Rather, one wants to feel that others need him, one is keen to experience affection and love. Participating in a terrorist organization gratifies this need by giving one a feeling that one belongs to a group of people like himself, that he has been accepted within a reference group, and that he has gained a really high status inside a broader community.

In a globalization-hit world, communication between ordinary, law-abiding and standardized people can set one's teeth on edge. More precisely, the standards and forms of this communication, as well as the subjective emotions accompanying them, obey Arthur Schopenhauer's axiom that the life of an ordinary man constantly vacillates between necessity and boredom. Even with his near and dear, including his own children, an average man communicates with the help of a few phrases that are existentially sluggish and mean nothing of importance: Good morning, time to get up. Have you done your work? Thank you, some more fish? Thank you, bye-bye. Nice to see you.

But communication between people whose life is hanging by a thread is transformed miraculously. Fleeting phrases, even an interjection take on a profoundly emotive personal meaning as if lit with the light of expected peril and triumph. Each remark dropped in the course of actions performed jointly with the comrades is accompanied by what psychoanalysts describe as the "oceanic feeling." Participating in a secret organization in the globalization age, this epoch of "the standardized and the lonely, "brings back the luxury of human communication" that other users have all but lost.

A consequence of globalization (making for the stunning fury and vigor of antiglobal protests) is the loss of emotional ties in the modem world. Industrial production, breakup of the traditional family structure, and dissolution of the stable societal model are factors eroding forms of communication (Fromm, 1998; Marcuse, 1964; Moscovici, 1985; Toffler, 1973). The communicative deficit is compensated for by the media and the Internet. A simplified and depersonalized "worldwide web" of no burdensome ties comes to replace a structuralized society braced with a complex and emotionally charged network of real interactions. A society organized with the help of a simplified communication network suffers from a deficit of identity, increased suggestibility, and a vacuum of human affections. In the 1960s, this complex was termed as the communication gap (Tkhostov, Surnov, 2003). Let us note in passing that the first surge of terrorism within the totally well-off Western civilization was precisely in that period of "communicationgap" reflection. The necessity and efficiency of stable communication communities is confirmed by numerous facts of better adaptation of mentally sick persons in archaic and paternalist societies. This paradox has been repeatedly mentioned by numerous epidemiological psychiatric studies (Kaplan, Sadok, 1988). The paradox consists in those communities enjoying a much lower level of medical aid than in advanced nations; but the qualities inherent in their public systems-affiliation, structurization, emotional support-make for a better effect than can be produced by any psychotropic drugs.

A remedy for unsociability is creating "denser" communication networks. Terrorist organizations belong in this category, for their members are linked by almost bloody, archaic relations. It is an escape route leading away from the "unbearable easiness of existence" that haunts the modern man. Communities passing through a stage of social formation change seem most vulnerable in this sense. Earlier communication means are in a state of collapse, while new ones are yet to take shape. Against this background, persons with an unstable self-identity and marginal personality organization tend to establish symbiotic relations, outside of which they constantly feel anxiety. 
Terrorism can also gratify the archaic and infantile craving for omnipotence. Any real activity, practically every individual fate is a consequence of numerous compromises with the "reality principle." Terrorist activities are, in a sense, "supra real." Quite possibly, certain concrete aims are articulated as an ideological justification. But historical experience testifies to the fact that terrorists, once in power, very rarely implement them. More often than not, their fight against an external enemy is transformed into the mobbing of former comrades-in-arms that stand in the way of their omnipotence.

A newly accepted member of an organization experiences a pleasant surge of emotion: he feels authorized and important, his life takes on a new meaning. What he feels is delight, almost narcotic euphoria and joyous excitement generated by the new life and the new role. A terrorist, possibly someone hailing from a small and poor village, almost becomes a citizen of the world permanently in the media focus-a media star! Even if his name is not mentioned, he all the same can see himself as a secret, but no less powerful, hero, whose name will sooner or later go down in history. One of the first terrorists to gain fame in this fashion was Herostratus of Ephesus: despite all efforts of contemporary society, his name has survived that of the architect who built the temple of Artemis he burned. In his analysis of the attempt on the life of Ronald Reagan that was perpetrated by a certain young man, who thus wished to win the good graces of a girl he loved, Sergey Dovlatov said one could achieve fame in many ways, like becoming a great painter, poet, scientist, or politician, but all of that was rather hard to achieve, wearisome, and there was no guarantee of success. Instead you could buy a gun in a store next door and your name would be splashed across all US papers and magazines.

The media consciousness is specific in that it does not make a contemporary hero out of a painter or a scientist, whose importance is only clear to a few chosen ones. Its hero is a newsmaker whose photograph is in every tabloid. So, which fate should be chosen by an infantile, hurt person that feels a small, insignificant cog in the global world? Under normal circumstances, a terrorist might have become a shepherd, or, at best, a policeman, whereas at the moment he takes women and children hostage, his muddled demands are instantly on air across the world TV net and the Prime Minister himself talks to him. Certainly it is not for long, but for an infantile consciousness this moment of glory is worth a whole colorless life. Infantile consciousness is not necessarily a consequence of a low education level or restricted cultural outlooks; it is the impossibility of accepting culture's restrictions. Members of the Red Brigades were successful by all standards; it was only after the media stopped covering their feats that the attractiveness of their demonic fates was on the wane.

This psychology explains what a rational point of view sees as an odd choice of victims among the top dignitaries of a state. Why a philistine, it would seem, must care about Pyotr Stolypin, the assassinated Prime Minister, or Emperor Alexander II, for whom he is supposed to feel nothing but class hatred? But in targeting those socially prominent figures, the terrorist calls into question the public hierarchy itself and emerges as someone who is able to accomplish these deities' destinies. And what then should a philistine think if such figures prove vulnerable?

Need for security. At first sight, this claim looks odd, for what can be farther from security than the danger-filled life of a terrorist? Here, however, we must introduce a distinction between the real and an illusory world. First, a terrorist has the illusion of being stripped of his singularity as someone included in a semi sacral community of sorts that consists of friends, soul mates, helpers, teachers, instructors, and omnipotent and omniscient leaders, who can make up for his lack of self-confidence. A terrorist's danger-filled life is protected by the illusory sensation that any situation is reliably controlled. Yet another benefit is that he no longer has to be incessantly preoccupied with his own financial and everyday well-being. An ordinary law-abiding person lives in a psychological space that obeys this rule: the more you own, the more you have to protect. A terrorist owns nothing, not even his own self. He does not belong to himself- he belongs entirely to the organization. The latter is solving all problems for him. It is omnipotent like the archaic imago (Bergeret, 2000). All that the person is required to do is to display an indisputable devotion that cannot but be rewarded. This is why its warrior is carefreealmost like the happy inhabitants of the primordial Ocean.

Having this need satisfied precisely by this method is of particular importance for the rank-and-file. But real, more or less reliable security is only achieved by terrorist leaders. And this is far from always the case, too. Here, like in other spheres, terrorist activities are primarily symbolic. Of course, a terrorist has to hide from the police and suffer discomfort while making, at a risk to his life, an explosive device in his 
kitchen. But at the semiotics level, he is a trickster, if not Lord God himself. Thus, from the angle of magical thinking, nothing can happen to him, for he is under a "spell," but if something does happen after all, he, as a symbolic subject, will live forever. This is yet another reason for the quasi-religious nature of terrorist activities that attract persons with a narcissistic personality disorder.

Need for new and strong impressions. Terrorism is an illusionridden disorderly activity that is free of any kind of banal commitments. A person immersed in the routine of everyday relations and social roles accepted once and for all is likely to be given a chance to live a unique life filled with most incredible adventures. An ordinary and orderly life gives a person the impression that his own existence is collapsing around him: a developed, recorded and predicted world tends towards a subjective disappearance (Tkhostov, 2002). Stuck in an excessively orderly world, a person has an intolerable sensation of losing his own Ego. Terrorism, in this sense, is a virtual game that brings back to the world its disappearing density. However, unlike the "Russian" roulette, risky behavior, or other auto-destructive activities, a terrorist's victims are other people. But their fate is not so important, because the case in point is a peculiar variant of play activities with unpredictable consequences. There is very much of a conspiracy game and initiation rites characterizing quite real terrorist organizations. This generic similarity between terrorism and play activities explains in part reduced sensitivity to victims' sufferings that appear depersonalized and unreal (Kaplan, and Sadok, 1988).

Some results of the classical experiments conducted by Stanley Milgram can be explained by a similar transformation of aggression into play activities and their growing symbolic character (Milgram, 1963). In a role-game environment characterized by anonymity and authoritative solutions, the subjects demonstrated an inadequate level and forms of aggression. This motivation is of particular importance for recruiting some relatively successful persons that suffer precisely from the easiness of being surrounding them rather than from its excessive density.

This is an answer to the question as to the wherefrom of the originally rich, educated and socially successful terrorists? In part this is explained by the identification vacuum characterizing some almost pathologically active personalities possessing clearly expressed-again, almost pathologically-dominant leader propensities. Occasionally they are charismatic personalities. The fact that terrorists, particularly terror organizers, have in their midst some educated owners of fortunes proves that the so-called radical socioeconomic causes of terrorism are not all and possibly not even the main roots of this plague of modern technologies.

The need for self-fulfillment. Joining an organization gives one an instantaneous, powerful and pleasant feeling of being authorized, important and ready to enjoy a new, meaningful life. A delight, bordering on narcotic euphoria, is accompanying the joyful excitement, which follows the acceptance of a new role and new life. The humiliated and the downtrodden become almost like gods. They are filled with the feeling of life's magnificence and meaning-fullness. And they perceive each subsequent step that involves them deeper and deeper into terror as a sign of sorts signaling an accumulation of hard-currency wealth. Alongside that, an opportunity is guaranteed of a relatively quick, not long and labor-consuming, acquisition of skills and techniques necessary for new luxurious new way of life. A subjectively truthful illusion is created of someone realizing all his best qualities.

An ordinary person's chances of self-fulfillment are restricted by numerous objective circumstances: his abilities, conditions of birth and upbringing, family and social surroundings, and, in the final analysis, even luck. His life requires of him protracted and prodigious efforts with no guaranteed reward. A terrorist's phantasmal self-fulfillment is unconnected with those onerous circumstances. His self-fulfillment is rapid, subjectively authentic, reliable, simple and clear. And it brings him to the top of the pantheon of heroes.

The need for symbolic self-identification (existential needs). The current Western civilization's normal social identity standards are at variance with the deep-down need for self-identification (from archetypal symbols to instinctive preliminary adaptations) a person gets from nature. Not only high-brow intellectuals but also land-tillers and stone masons need to measure themselves against and at least unconsciously identify with something more majestic and beautiful than the correctly drawn up passport or driving license and a decent state of debt obligations. It is not enough for a human individual to be an obedient follower of traffic rules and punctual taxpayer. He feels bored within this self-identification framework. He seeks to be something bigger, more important, God-like.

It is this "chronic identification deficiency" of Western society's social standards that explains what we see as the unprecedented in scale and quite unexpected in the 21st century success of various brands of 
religious and political fundamentalism. Even more often these concepts are offered as a fantastic combination, for example, of terrorism and Islam. It is not important that they are primitive. Nor is it important that they are irrational and contradict logic. What is important is that they fill the vacuum and provide answers to all the questions a subject needs, no matter how incorrect these answers might be.

Even cognitively simple and uneducated persons, such as the majority of ordinary members of terrorist organizations, to some or other extent feel the need to rationalize the meaning of their life and to bring it into proper correlation with the powerful forces of universal harmony that are opposed to universal chaos. In their dreams, the humiliated and the downtrodden become God-like. They can amply feel the splendor and rationale of living. The beauty of terror is revealed to the chosen ones in the same way as the phantom of Superman was revealed to Friedrich Nietzsche: "Ah, my brethren! Of what account are-the Gods to me!" (Nietzsche, 1910). An analysis of terrorists' deep-down motivation can reveal the importance and considerable significance of the feeling of belonging to a secret and powerful organization: it helps successful self-identification while preserving the highest level of self-evaluation. Traceable to the need of affiliation, this motivation line is archetypal and almost instinctive, and, as such, quite deep-lying and powerful. Terrorism's meaning-forming function is also in that it infuses with higher aims the life of an ordinary person thrown on the bottom of an existential vacuum.

The connection between religious fundamentalism and terrorism demonstrates yet another important psychological phenomenon, to wit, the subjective impossibility of bearing the vacuum of the higher meaning, that is characteristic of everyone, not only the reflectionprone intellectual. An ordinary person needs this no less, for "the death of God" (Renault, 1989) makes him feel his own total loneliness and teleological absurdity. As you watch certain terrorists and listen to what they say, you can least of all suppose that their passion is based on a true religious feeling that should accord more with even-handedness and tolerance. Most of all religious fanaticism resembles what psychoanalysts describe as psychological defense via "reaction formation" that disguises a fundamental uncertainty behind a show of conviction (Bergeret, 2000). The current religious revival is in itself a reaction to religious emancipation.
"The death of God" can only seemingly free a person from the burden of moral obligations. Inside, it contains a source of the universal fear of the final separation. The idea of God used to help mitigate this fear, because there was always the figure of a universal idealized father, stern but just, and the merciful Mother of God, the Media-tress. Of course, this is linked to certain dangers, such as the hypothetical possibility of Last Judgment. But at least the Judgment guaranteed after-life justice and ultimate protection. Bereft of it, man is deprived of any guarantees whatsoever. He is free, but he is totally lonely. The search for the lacking moral authority helps mitigate this feeling: it may be so intolerable that any newly-found authority should be super-idealized. And the narrower a person's scope for self-sustained fear - of - loneliness compensation, the more his attachment will be fixated on the newly-found ideal which gives him the higher meaning, while simultaneously justifying his baser needs, such as aggression, that turns into a form of service to the idea.

Mircea Eliade believed that the fear felt by the contemporary Western intellectual was due to his profound dissatisfaction with the obsolete forms of historically existing Christianity and to his passionate desire to shed his ancestral faith, a desire accompanied by an unexplainable feeling of guilt. "...As if he himself had killed a God in whom he could not believe but whose absence he could not bear...the success of certain ideas or ideologies reveals to us the spiritual and existential situation of all those for whom these ideas or ideologies constitute a kind of soteriology" (Eliade, 1967).

This turns the ideology of terrorism into a variant of some pseudoreligion or makes it a component of some existing religious doctrine. Then, terrorist activities turn into conscious soteriological activities that give a person the right to salvation and fill his life with the higher meaning. For a suicide bomber, the death of his body is just the end of what is not the greater or most important part of his life. It is the beginning of a higher, meaningful and valuable existence.

$$
\star * *
$$

Both students and members of terrorist organizations rarely articulate (put into words and rationalize) answers to questions about whether they feel tempted, or attracted, or expect personal benefits as they take the decision to join a terrorist movement. Our analysis of answers to this group of questions reveals that this personal decision is often based 
on the feeling that one is given a chance for a rapid and relatively easy gratification of fundamental human needs.

Thus, though the prerequisites to modern terrorism are primarily economic and social crises, terrorism is based on some deep-lying qualities of human nature.

The values- and ideas-related basis of terrorism is the inner conviction that one serves the absolute, the higher and the only truth, something that results in fanaticism and readiness to assert it by any means.

Terrorism is a multi-disciplinary, including psychological, problem because the involvement in terrorist activities is based on the use and manipulation of some chronically unsatisfied needs of a considerable part of people. As such, terrorism must be appropriately studied.

The task of launching a psychological study of the process whereby people are involved in terrorist activities implies that a fundamental conceptual framework should first be developed that would enable researchers to effectively correlate and coordinate different, quite numerous and heterogeneous types of analysis and approaches to the problem, thus evolving an increasingly perfect theory. In practice this means suggesting methods of scientific identification of some significant points in the process under study, something that would essentially assist in improving the entire system of the world community's counter-terrorist and anti-terrorist efforts.

The methodologically correct way to answer the question why people may wish to be involved in terrorist activities lies through analyzing what they do (or are allowed to do) as terrorists and how they acquire and preserve the motivational involvement in specifically terrorist undertakings and actions.

\section{References}

Bergeret, J. (2000). Psychologiepathologique: thiorie et clinique. Paris.

De Mijolla, A. (2002). Dictionnaire international de la psychanalyse, 2. Paris.

Eliade, M. (1967). Occultism, Witchcraft, and Cultural Fashions: Essays in Comparative Religions. Chicago.

Fromm, E. (1998). To Have or to Be? New York.

Fukuyama, F. (2002). Our Post-human Future: Consequences of the Biotechnology. New York.

Horgan, J. (2005). The Psychology of Terrorism. London; New York.
Hudson, R. (2005). The Sociology and Psychology of Terrorism. Who Becomes a Terrorist and Why? Honolulu.

Kaplan, H., and Sadok, B. (1988). Clinical Psychiatry. Baltimore.

Leont'ev, A. (1959). Problemy razvitija psihiki [Problems of Psyche's Development]. Moskva: APN RSFSR.

Leont'ev, A. (1975). Deyatel'nost'. Soznanie. Lichnost' [Activities. Consciousness. Personality]. Moskva: Politizdat.

Marcuse, H. (1964). One-Dimensional Man. New York.

Milgram, S. (1963). Behavioral Study of Obedience. Journal of Abnormal and Social Psychology, 67. P. 371-378.

Moscovici, S. (1985). The Age of the Crowd: A Historical Treatise on Mass Psychology. New York.

Nietzsche, F. (1910). Thus Spoke Zarathustra: A Book for Everyone. London.

Renault, A. (1989). L'ere de l'individu: contribution a une histoire de la subjectivite. Paris.

Stout, Ch. (ed.) (2004). Psychology of Terrorism: Coping with the Continuing Threat. Westport (Conn.); London.

Tkhostov, A. (2002). Psihologija telesnosti [Psychology of Corporeality]. Moskva: Smysl.

Tkhostov, A., Surnov, K. (2003). Sovremennye tehnologii i novye granitsy sotsial'nyh determinatsiy normy i patologii [Modern Technologies and New Boundaries of the Sociocultural Determination of Norm and Pathology]. In A.L. Zhuravlev, N.V. Tarabrinva (eds.). Psihologiya: Sovremennye napravleniya mezhdistsiplinarnyh issledovaniy. Moskva: IP RAN. P. 66-79.

Toffler, A. (1973). The Culture Consumers. New York. 